\title{
Inducible nitric oxide synthase expression in melanoma: implications in lymphangiogenesis
}

\author{
Daniela Massi ${ }^{1}$, Maria C De Nisi ${ }^{2}$, Alessandro Franchi ${ }^{1}$, Vasileios Mourmouras ${ }^{2}$, \\ Gianna Baroni ${ }^{1}$, John Panelos ${ }^{1}$, Marco Santucci ${ }^{1}$ and Clelia Miracco ${ }^{2}$ \\ ${ }^{1}$ Department of Human Pathology and Oncology, University of Florence, Florence, Italy and ${ }^{2}$ Department of \\ Human Pathology and Oncology, University of Siena, Siena, Italy
}

\begin{abstract}
Cutaneous melanoma preferentially metastasizes via the lymphatic route. However, the mechanisms of lymphatic invasion and metastasis to regional lymph nodes are poorly understood. Nitric oxide is a free radical molecule synthesized from L-arginine by nitric oxide synthases that plays a critical role in various physiological and pathological processes, including tumor growth and angiogenesis. We have tested whether inducible nitric oxide synthase expression correlates with lymphatic vessel density identified with D2-40 antibody and/or blood microvessel density identified with CD105/endoglin in a series of melanocytic nevi $(n=28)$ and cutaneous melanomas $(n=38)$, representative of various pT. Inducible nitric oxide synthase expression was significantly lower in melanocytic nevi in comparison with primary and metastatic melanomas $(P<0.001)$. Mean microvessel density was significantly higher in primary and metastatic melanomas in comparison with melanocytic nevi $(\boldsymbol{P}<\mathbf{0 . 0 0 1}$ for intratumoral and $\boldsymbol{P}=\mathbf{0 . 0 0 1}$ for peritumoral vessels). Vertical growth phase melanomas showed a higher intratumoral microvessel density in comparison with radial growth phase melanomas $(\boldsymbol{P}=0.02)$. The number of peritumoral lymphatics was significantly lower in nevi as compared with primary and metastatic melanomas $(P=\mathbf{0 . 0 1})$. No correlation between microvessel or lymphatic vessel and clinical outcome was found in melanomas. A significant direct correlation was observed between inducible nitric oxide synthase immunostaining in melanocytic tumor cells and the density of lymphatic vessels (peritumoral: $P=0.001$; intratumoral: $\boldsymbol{P}=\mathbf{0 . 0 8}$ ), and the density of peritumoral blood microvessel $(\boldsymbol{P}=0.02)$. Our findings support the hypothesis that inducible nitric oxide synthase is implicated not only in blood, but also in lymphatic vascular neoformation in melanoma. Mechanistic studies are needed to address the possibility that inducible nitric oxide synthase controls lymphangiogenesis, dissemination and lymphatic borne metastases.
\end{abstract}

Modern Pathology (2009) 22, 21-30; doi:10.1038/modpathol.2008.128; published online 25 July 2008

Keywords: iNOS; CD105; D2-40; microvessel density; melanoma; nevi

Cutaneous melanoma metastasizes at least initially through the lymphatic route and lymph node metastasis is currently still a major determinant for patients staging and clinical management. The mechanisms of lymphatic invasion and metastasis to regional lymph nodes are mostly unknown and whether human tumors promote de novo lymphangiogenesis is still unclear. Although the pathways that regulate tumorrelated angiogenesis have been partially investigated, poor information is available on the processes that result in lymphangiogenesis in melanoma.

Nitric oxide (NO) is a diatomic free radical molecule synthesized from L-arginine by NO synthases (NOS) that plays a critical role in various

Correspondence: Professor D Massi, Dipartimento di Patologia Umana ed Oncologia, Università degli Studi di Firenze, Viale GB Morgagni 85, I-50134 Firenze, Italia.

E-mail: daniela.massi@unifi.it

Received 25 March 2008; revised 13 June 2008; accepted 18 June 2008; published online 25 July 2008 physiological and pathological processes, including tumor growth. Although the $\mathrm{Ca}^{2+}$-dependent isoforms NOS1 and NOS3 are constitutively expressed by neural and endothelial cells, the $\mathrm{Ca}^{2+}$-independent form (NOS2 or iNOS) can be induced by many cell types upon stimulation by inflammatory cytokines and is able to rapidly generate high amounts of NO. ${ }^{1}$ In cancer, although high levels of NO may exert cytostatic or cytotoxic functions, the constitutive production of low levels of intracellular NO has been associated with tumor growth. ${ }^{2-5}$

Tumor-cell-derived NO has been proposed to be an important mediator of tumor angiogenesis and metastasis formation by directly inducing vessel dilation, promotion of blood flow and vascular permeability and endothelial cell proliferation through upregulation of vascular endothelial growth factor (VEGF) and basic fibroblastic growth factor. ${ }^{6,7}$ In addition, more recent observations indicate that NO is involved in the regulation of lymphatic vessels permeability and flow ${ }^{8}$ and we have recently 
demonstrated that iNOS activity correlated with lymphangiogenesis and spread to lymph nodes in head and neck squamous cell carcinoma. ${ }^{5}$ It is possible that in the tumor microenvironment NO stimulates angiogenesis and/or lymphangiogenesis cooperatively with other proangiogenic and lymphangiogenic growth factors.

The pleiotropic actions of NO have been also reported in melanoma. NO release induces antiapoptotic effects, prolonging the survival of melanoma cells in vitro. ${ }^{9-11}$ Data from our laboratory and from others reported iNOS expression in the vast majority of melanoma tissue specimens and cultured melanoma cells, ${ }^{6,12-16}$ suggesting a role for iNOS in the development and progression of cutaneous melanoma. However, to our knowledge, no study has investigated the expression of iNOS in relation to angiogenesis of lymphatic and blood vessels in melanocytic lesions.

The extent of tumor (lymph)angiogenesis is usually estimated by lymphangiogenic and angiogenic microvessel density. Here, we have tested whether iNOS expression in melanocytes or melanoma cells correlates with the density of intratumoral and peritumoral microvessels and lymphatics in melanocytic nevi and melanomas, identified with CD105/endoglin (a marker of proliferating endothelial cells and angiogenic blood vessels) and D2-40 antibody (a new specific antibody for lymphatic endothelial cells, LECs). The relationship between (lymph)angiogenesis and various clinicopathological features, including the clinical outcome, in malignant melanoma patients was also investigated.

\section{Materials and methods}

\section{Patients and Specimen Selection}

Tissue specimens were retrospectively obtained from the archive of the Department of Human Pathology and Oncology, University of Siena. The study series included 66 consecutive cutaneous melanocytic lesions, diagnosed in the last 2 years. There were melanocytic nevi $(n=28)$ and malignant melanomas $(n=38)$. Melanocytic nevi were distributed as follows: common melanocytic nevi $(n=4)$, so-called atypical, 'dysplastic' nevi $(n=14)$, Spitz/ Reed nevi $(n=7)$ and blue nevi $(n=3)$. Melanoma samples included: in situ melanomas $(n=4)$, primary invasive melanomas (19 in vertical growth phase, VGP, and 6 in radial growth phase, RGP) and melanoma metastases $(n=9)$. For each melanoma case, the patients' charts were analyzed for age at diagnosis, sex, anatomic location and patient outcome. Follow-up ranged from 11-60 months (mean, 16.9 months; median, 15 months). Mean and median follow-up of patients who did not develop recurrences were 16.7 and 15 months, respectively. Histopathologic slides were reviewed for Breslow thickness, Clark's level, histotype, ulceration, growth phase and mitotic activity. The main clinical and pathological features of the whole series are summarized in Table 1. Among primary melanoma cases, 11 patients were submitted to sentinel lymph node biopsy. Sentinel lymph nodes were negative in 10 cases and positive in 1 patient (with subsequent negative elective lymphadenectomy). Among cases undergoing disease progression, local recurrences were experienced in two cases, lymph node metastases in one case and distant metastasis (brain) in one additional patient.

\section{Immunohistochemical Analysis (iNOS, CD105, D2-40)}

The immunohistochemical analyses were performed on $4 \mu \mathrm{m}$ thick sections from formalin-fixed and paraffin-embedded archival tissues, using the streptavidin-biotin peroxidase complex method. The conditions were optimized for each antibody. Antihuman iNOS rabbit polyclonal antibody (Biomol Research Laboratories, Plymouth Meeting, PA, USA) at 1:600 dilution was applied following antigen retrieval that was performed on dewaxed and rehydrated sections totally immersed in $10 \mathrm{mM}$ sodium citrate buffer $(\mathrm{pH}$ 6.0) with heating for $10 \mathrm{~min}$ at $500 \mathrm{~W}$ output in household microwave. The sections then were allowed to cool down to room temperature (RT) for $20 \mathrm{~min}$. Additional sections from the same specimens were deparaffined in Bio-Clear (Bio-Optica, Milan, Italy) hydrated with grade ethanol concentration until distilled water and placed in $3 \%$ hydrogen peroxide $\left(\mathrm{H}_{2} \mathrm{O}_{2}\right)$. for blocking endogenous peroxidase. Antigen retrieval by microwave pretreatment (Microwave MicroMed T/T Mega, Milestone, Bg, Italy) in citrate buffer $10 \mathrm{mM}$ ( $\mathrm{pH}$ 6.0) for $30 \mathrm{~min}$ was followed by incubation with the monoclonal antibody D2-40 (Signet Laboratories, Dedham, MA, USA; prediluted) overnight at $4^{\circ} \mathrm{C}$. Bound antibodies were visualized using aminoethylcarbazole (AEC, LabVision Corporation) as chromogen. The sections were lightly counterstained with Mayer hematoxylin. AntiCD105 (MoAb, clone SN6H, Dako, Milan, Italy) at dilution 1:900 was applied overnight on dewaxed sections at $4{ }^{\circ} \mathrm{C}$. Signal amplification was obtained by the Ultravision LP Detection System AP polymer (Lab Vision, Bio-Optica, Milan). As chromogen, new fucsin (Dako) was used, developing a cytoplasmic red stain in positive cells. Sections were counterstained with Harris hematoxylin. Negative controls were obtained by replacing the specific antibody with nonimmune serum immunoglobulins at the same concentration of the primary antibody. For positive controls, samples of normal upper airway epithelium were used.

\section{Evaluation of Immunohistochemistry and Quantitative Assessment of Microvessel Density}

The immunohistochemically stained sections were independently reviewed by two observers. To score 
Table 1 Clinicopathological data of primary cutaneous melanoma cases $(n=29)$

\begin{tabular}{|c|c|c|c|c|c|c|c|c|}
\hline Case & Age/sex & Site & Histotype & Thickness & Level & Ulceration & Growth phase & Mitotic activity $\left(\mathrm{mm}^{2}\right)$ \\
\hline 1 & $64 / F$ & Thigh & SSM & - & I & Absent & Radial & - \\
\hline 2 & 71/M & Leg & SSM & - & I & Absent & Radial & - \\
\hline 3 & $48 / \mathrm{F}$ & Abdomen & SSM & - & I & Absent & Radial & - \\
\hline 4 & $70 / F$ & Thigh & SSM & - & I & Absent & Radial & - \\
\hline 5 & $46 / \mathrm{M}$ & Abdomen & SSM & 0.28 & II & Absent & Radial & - \\
\hline 6 & $72 / \mathrm{M}$ & Back & SSM & 0.23 & II & Absent & Radial & - \\
\hline 7 & $48 / \mathrm{M}$ & Abdomen & SSM & 0.35 & II & Absent & Radial & 1 \\
\hline 8 & $77 / \mathrm{F}$ & Back & SSM & 0.28 & II & Absent & Radial & - \\
\hline 9 & $45 / \mathrm{F}$ & Knee & SSM & 0.31 & II & Absent & Radial & - \\
\hline 10 & $44 / \mathrm{F}$ & Back & SSM & 0.42 & III & Absent & Radial & - \\
\hline 11 & $78 / \mathrm{M}$ & Shoulder & SSM & 6.50 & IV & Present & Vertical & - \\
\hline 12 & $70 / \mathrm{M}$ & Arm & SSM & 2.40 & IV & Absent & Vertical & 1 \\
\hline 13 & $57 / \mathrm{F}$ & Leg & SSM & 2.10 & IV & Absent & Vertical & 1 \\
\hline 14 & $37 / \mathrm{M}$ & Trunk & SSM & 0.77 & IV & Present & Vertical & 1 \\
\hline 15 & $46 / \mathrm{M}$ & Back & SSM & 2.60 & IV & Present & Vertical & 2 \\
\hline 16 & $79 / \mathrm{F}$ & Leg & SSM & 2.80 & IV & Present & Vertical & 7 \\
\hline 17 & $65 / \mathrm{F}$ & Shoulder & SSM & 2.70 & IV & Present & Vertical & 3 \\
\hline 18 & $80 / \mathrm{M}$ & Back & SSM & 2.80 & IV & Present & Vertical & 30 \\
\hline 19 & $68 / \mathrm{F}$ & Arm & SSM & 0.95 & IV & Absent & Vertical & 1 \\
\hline 20 & $68 / \mathrm{F}$ & Back & SSM & 0.35 & III & Absent & Vertical & 1 \\
\hline 21 & $53 / \mathrm{M}$ & Trunk & SSM & 4.20 & IV & Absent & Vertical & 60 \\
\hline 22 & $34 / \mathrm{F}$ & Trunk & SSM & 0.46 & III & Absent & Vertical & - \\
\hline 23 & $69 / \mathrm{M}$ & Back & SSM & 1.20 & IV & Present & Vertical & 15 \\
\hline 24 & $28 / F$ & Arm & SSM & 0.55 & III & Absent & Vertical & 6 \\
\hline 25 & $80 / \mathrm{M}$ & Ear & NM & 14.0 & $\mathrm{~V}$ & Present & Vertical & 2 \\
\hline 26 & $87 / \mathrm{F}$ & Back & NM & 4.10 & IV & Present & Vertical & - \\
\hline 27 & $77 / \mathrm{M}$ & Scalp & NM & 11.0 & IV & Absent & Vertical & 40 \\
\hline 28 & $77 / \mathrm{M}$ & Toe & NM & 10.00 & V & Present & Vertical & - \\
\hline 29 & $85 / \mathrm{M}$ & Foot & ALM & 4.10 & IV & Present & Vertical & 2 \\
\hline
\end{tabular}

ALM, acral lentiginous melanoma; F, female; M, male; NM, nodular melanoma; SSM, superficial spreading melanoma.

the iNOS staining pattern, only melanocytic cells with evidence of cytoplasmic staining were considered positive. The results were expressed according to semiquantitative criteria as: negative staining (score 0); $1-20 \%$ (score +); $21-50 \%$ of positive cells (score ++ ) and more than $50 \%$ of positive cells (score +++ ). iNOS staining intensity was recorded as weak, moderate or strong.

To evaluate mean vessel density by CD105 and D2-40, the sections were scanned at low magnifications $(\times 25$ and $\times 100)$ to identify the most vascular areas of the tumor (hot spots). In thin lesions (junctional melanocytic nevi, in situ and thin melanomas), evaluation was limited to the tumorstroma boundary within one high power field (HPF, $\times 40$ objective and $\times 10$ eyepiece). In thick lesions (compound nevi; vertical growth phase melanomas) and metastases, vessel counts were performed in: (1) central/vertical growth phase area, (2) at the peripheral tumor-stroma boundary, within one HPF in the tumor invasive front. When a RGP was present in a thick melanoma, it was also evaluated, as performed in thin lesions. Vessels more than one-half HPF away from above-defined areas, as well as vessels inside necrotic and ulcerated areas were not counted. Within these areas, from a minimum of 5 to a maximum of 10 randomly chosen fields at $\times 400$ magnification (HPF, $0.16 \mathrm{~mm}^{2}$ per field) were evaluated by two independent observers and the mean value was calculated for statistical analysis.

\section{Statistical Analysis}

Statistical tests were performed using SPSS software (release 14.0, SPSS Inc., Chicago, IL, USA). MannWhitney $U$-test was employed to compare two groups of unpaired values, whereas for comparisons between groups of more than two unpaired values, we employed the Kruskal-Wallis H-test. The correlation between two parameters was reported as Spearman's product-moment correlation coefficients ( $r s)$. All $P$-values resulted from the use of two-sided statistical tests; $P<0.05$ was considered significant.

\section{Results}

iNOS immunoreactivity was limited to the cell cytoplasm. The basal and suprabasal epidermal layers and the adnexal epithelium constantly showed a strong and diffuse iNOS positivity. Staining was often observed in macrophages and, in some cases, in endothelial cells, whereas lymphocytes were negative. Overall, iNOS immunostaining was significantly lower in melanocytic nevi in comparison with primary and metastatic melanomas (negative/score + vs score ++ /score +++ , $P<0.001, \quad \chi^{2}$-test; Table 2). The large majority of common acquired nevi showed absent to low and weak iNOS immunostaining (Figure 1). In common acquired nevi showing maturation in the reticular 
Table 2 Distribution of iNOS immunohistochemical expression in a series of melanocytic nevi, primary and metastatic melanomas $(n=66)$

\begin{tabular}{|c|c|c|c|c|}
\hline & iNOS-, n (\%) & iNOS, $1-20 \% \mathrm{n}(\%)$ & iNOS, $21-50 \%$ n (\%) & iNOS, $>50 \% \mathrm{n}(\%)$ \\
\hline Melanocytic nevi $(n=14)$ & $9(64.3)$ & $1(7.1)$ & $3(21.5)$ & $1(7.1)$ \\
\hline Atypical 'dysplastic’ nevi $(n=14)$ & $9(64.3)$ & $3(21.5)$ & - & $2(14.2)$ \\
\hline Radial growth phase melanomas $(n=10)$ & $3(30.0)$ & $1(10.0)$ & $4(40.0)$ & $2(20.0)$ \\
\hline Vertical growth phase melanomas $(n=19)$ & $3(15.7)$ & $8(42.1)$ & $4(21.1)$ & 4 (21.1) \\
\hline Melanoma metastases $(n=9)$ & $3(33.4)$ & $2(22.2)$ & $2(22.2)$ & $2(22.2)$ \\
\hline
\end{tabular}
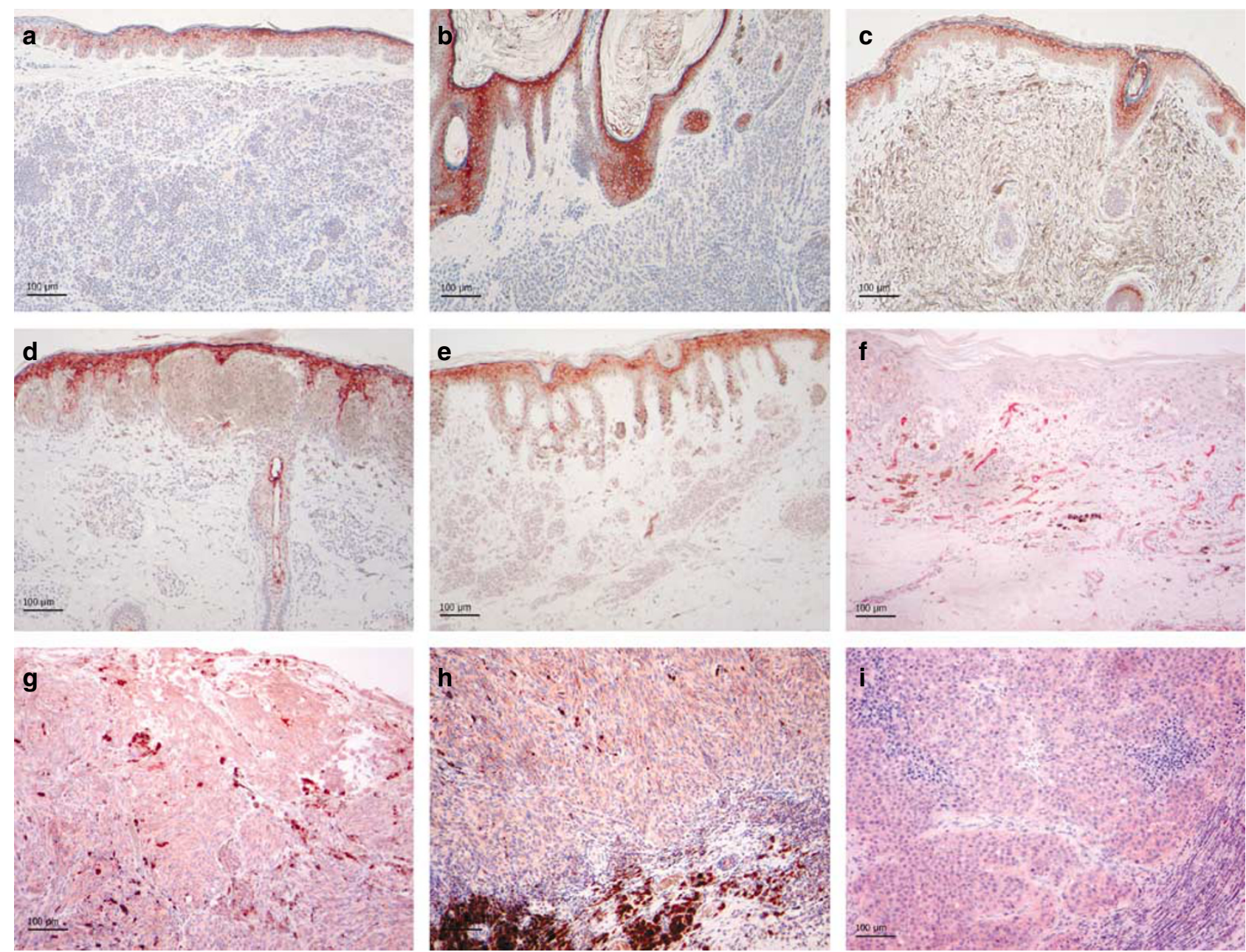

Figure 1 (a) Nevus cells in a common acquired nevus are iNOS - whereas the basal and suprabasal epidermal layers are diffusely positive. (b) Immunostaining for iNOS in a congenital nevus; (c) elongated, dendritic melanocytes in a blue nevus are iNOS-; (d) pigmented spindle melanocytes in Reed nevus are iNOS - (original magnification $\times 10$; scale bar, $100 \mu \mathrm{m})$; (e) atypical, so-called 'dysplastic' nevus showing scattered iNOS + melanocytes at the junction; (f) in situ melanoma with regression shows iNOS positivity in melanoma cells as well as in perilesional blood vessels; (g) iNOS positivity in nodular ulcerated VGP melanoma; (h) iNOS positivity in melanoma cells at the tumor invasive front, nearby regression; (i) iNOS positivity in metastatic melanoma cells within a lymph node (a-i: original magnification $\times 10$; scale bar, $100 \mu \mathrm{m})$.

dermis (either toward neuroid structures or toward small, type $\mathrm{C}$ nevus cells) a decrease in the intensity of the immunoreaction was observed. Epithelioid and spindle melanocytes in Spitz's and Reed nevi were either iNOS - or weakly and focally stained. The majority of atypical, 'dysplastic' nevi expressed low to absent iNOS, although in 2 out of 14 cases showing marked cytological atypia, a diffuse iNOS immunoreaction was observed in more than $50 \%$ of melanocytes. Elongated, dendritic melanocytes in blue nevi were constantly iNOS-. No significant correlation was found between iNOS expression and disease progression, clinical outcome as well as other histopathologic parameters, such as ulceration, histotype, level and mitotic activity. In melanomas, areas of strong iNOS expression in 

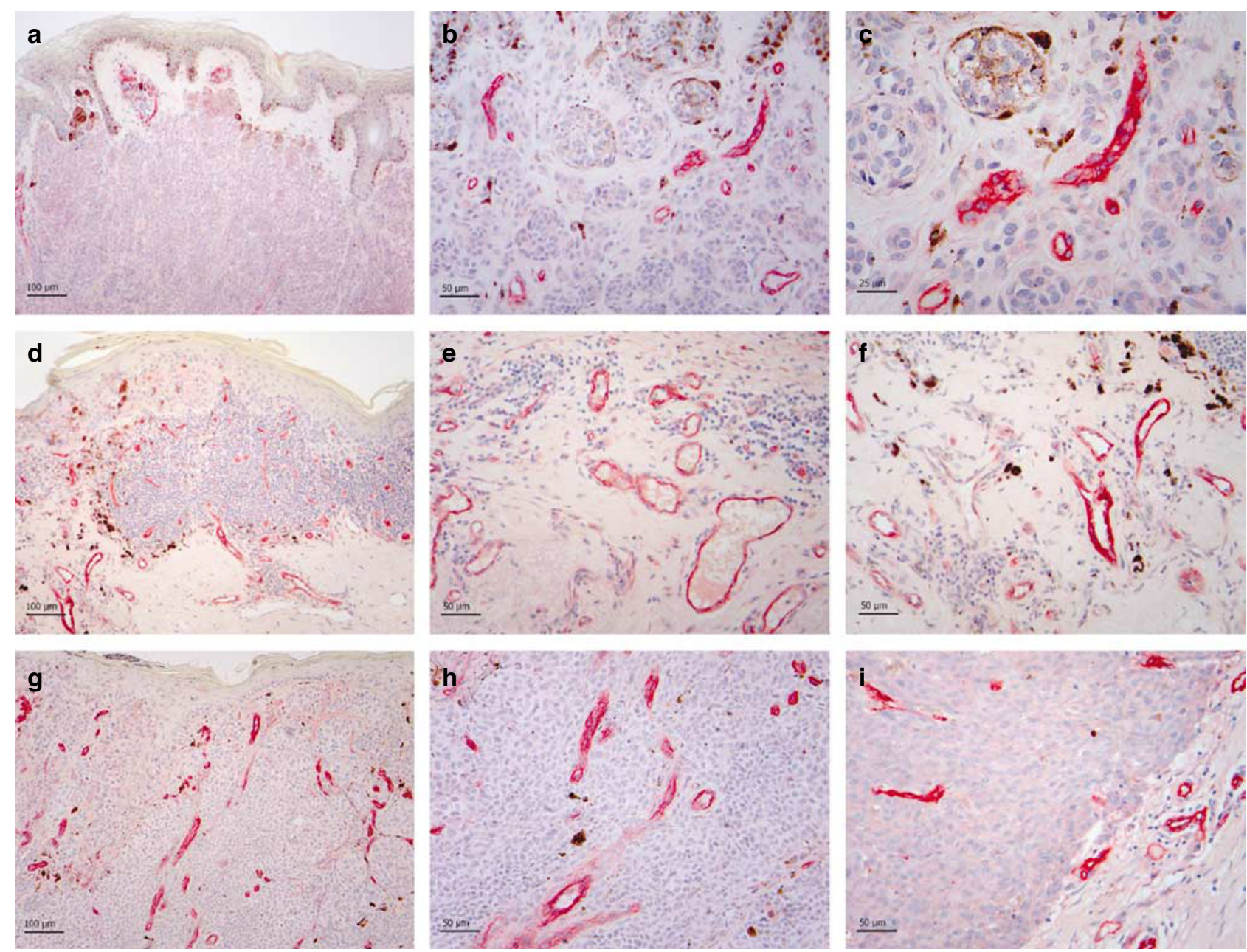

Figure 2 (a) Immunostaining for CD105 in a common acquired nevus demonstrates rare vascular structures in the superficial portions of the lesion (original magnification $\times 10$; scale bar, $100 \mu \mathrm{m}$ ); (b) CD105 + blood vessels surrounded by nests of benign melanocytes (original magnification $\times 20$; scale bar, $50 \mu \mathrm{m}$ ); (c) at higher power CD105 staining is observed in both luminal and cytoplasmic location in endothelial cells decorating newly formed vessels (original magnification $\times 40$; scale bar, $25 \mu \mathrm{m}$ ); (d) CD105 in RGP melanoma shows numerous strongly positive vessels mostly in peritumoral location (original magnification $\times 10$; scale bar, $100 \mu \mathrm{m}$ ); (e) at higher power large CD105 + blood vessels are seen in the stroma at peritumoral location (original magnification $\times 20$, scale bar $50 \mu \mathrm{m}$ ); (f) in the context of regression, strongly CD105 + blood vessels intermingled with melanophages, fibroplasia and a mixed inflammatory infiltrate (original magnification $\times 20$; scale bar, $50 \mu \mathrm{m}$ ); (g) thick VGP melanomas associated with numerous CD105 + intratumoral vessels (original magnification $\times 10$; scale bar, $100 \mu \mathrm{m})$; (h) at higher power intratumoral vessels show strong CD105 immunostaining (original magnification $\times 20$; scale bar, $50 \mu \mathrm{m}$ ); (i) intratumoral and peritumoral CD105 + vessels at the tumor invasive front in a VGP melanoma (original magnification $\times 20$; scale bar, $50 \mu \mathrm{m}$ ).

neoplastic cells were associated with highly iNOS immunoreactive blood vessels. A high iNOS positivity was generally observed in endothelial cells in the context of areas of regression. Conversely, the blood vasculature in melanocytic nevi was generally iNOS-. In metastatic melanomas, a moderate to strong iNOS staining was observed in 6 out of 9 cases $(66.6 \%)$. Neoplastic cells at the periphery of metastases were more intensely and diffusely stained than those located in the center of the tumor mass.

CD105 staining was observed in both luminal and cytoplasmic location in endothelial cells in newly formed vessels (Figure 2). The density of CD105 + blood vessels appeared higher in nevi and melanomas than in neighboring normal human skin (data not shown). The epidermis and adnexal structures were constantly CD105-. In melanocytic lesions, the intensity of staining in endothelial cells was variable, although in vessels within areas of regression in melanomas the intensity was constantly strong. Focally, CD105 positivity was observed also in melanoma cells, with cytoplasmic and focal membranous pattern, and, less commonly, also in nevus cells in melanocytic nevi. Table 3 summarizes the distribution of CD105 + and D2-40 + vessel density in the whole series of melanocytic nevi, primary and metastatic melanomas. Using CD105 antibody, mean intratumoral and peritumoral microvessel density was significantly higher in 
Table 3 Distribution of CD105+ and D2-40+ vessel density in a series of melanocytic nevi, primary and metastatic melanomas ( $n=66)$

\begin{tabular}{lcccc}
\hline & $\begin{array}{c}\text { CD105+ intratumoral } \\
\text { vessels mean } \pm \text { s.d. }\end{array}$ & $\begin{array}{c}\text { CD105+ peritumoral } \\
\text { vessels mean } \pm \text { s.d. }\end{array}$ & $\begin{array}{c}\text { D2-40+ intratumoral } \\
\text { vessels mean } \pm \text { s.d. }\end{array}$ & $\begin{array}{c}\text { D2-40+ peritumoral } \\
\text { vessels mean } \pm \text { s.d. }\end{array}$ \\
\hline $\begin{array}{l}\text { Melanocytic nevi }(n=14) \\
\begin{array}{l}\text { Atypical 'dysplastic' nevi } \\
(n=14)\end{array}\end{array}$ & $3.2 \pm 1.0$ & $3.4 \pm 0.9$ & $1.8 \pm 1.2$ & $2.1 \pm 0.7$ \\
$\begin{array}{l}\text { Radial growth phase } \\
\text { melanomas }(n=10)\end{array}$ & $3.7 \pm 1.5$ & $4.9 \pm 0.9$ & $1.1 \pm 1.2$ & $1.5 \pm 0.2$ \\
$\begin{array}{l}\text { Vertical growth phase } \\
\text { melanomas }(n=19)\end{array}$ & $7.2 \pm 2.1$ & $4.0 \pm 4.8$ & $2.4 \pm 1.1$ & $3.4 \pm 0.8$ \\
$\begin{array}{l}\text { Melanoma metastases } \\
(n=9)\end{array}$ & $7.2 \pm 2.1$ & $8.1 \pm 2.7$ & $2.5 \pm 1.6$ & $3.8 \pm 1.5$ \\
\end{tabular}

*Mean vessel density values per HPF (calculated from a minimum of five to a maximum of 10 randomly chosen fields at $\times 400$ magnification) (HPF, $0.16 \mathrm{~mm}^{2}$ per field).

primary (both radial and vertical growth phase) and metastatic melanomas in comparison with melanocytic nevi (Figure 3, $P<0.001$ for intratumoral vessels and $P=0.001$ for peritumoral vessels, respectively, Kruskal-Wallis H-test). Among primary melanomas, VGP melanomas showed a higher intratumoral microvessel density in comparison with RGP melanomas $(P=0.02$, Mann-Whitney $U$-test). However, no significant correlation was found between microvessel density and other clinicopathological variables, including ulceration, level, histotype, mitoses, location and clinical outcome.

D2-40 stained endothelial cells of lymphatic vessels whereas endothelial cells rimming blood vessels were negative. All the D2-40-stained vessels were typically thin walled, lined by a single layer of attenuated endothelial cells lacking pericytes, and appeared partially collapsed. Lymphatic vessels were observed both in the context of the tumor mass and in the peritumoral area, but were found more numerous in the peritumoral area. Intratumoral lymphatics often showed numerous tiny lumina whereas the peritumoral lymphatics appeared larger and displayed more dilated open lumina (Figure 4). In some melanoma cases, lymphatic vessels were seen in close association with mononuclear cells, lymphocytes and macrophages. No D2-40 immunostaining was identified in nevus cells or melanoma cells. The number of peritumoral lymphatics was significantly lower in melanocytic nevi as compared with both primary (both in radial and vertical growth phase) and metastatic melanomas (Figure 5, $P=0.01$, Kruskal-Wallis H-test). Conversely, no differences were demonstrated between melanocytic nevi, primary and metastatic melanomas concerning the intratumoral lymphatic vessel density $(P=0.27$, Kruskal-Wallis H-test). Within primary melanomas, we found no correlation between lymphatic vessel density and other clinicopathological variables, including ulceration, level, histotype, mitoses and clinical outcome.

When considering the whole series (melanocytic nevi, primary and metastatic melanomas), a direct correlation was observed between iNOS expression

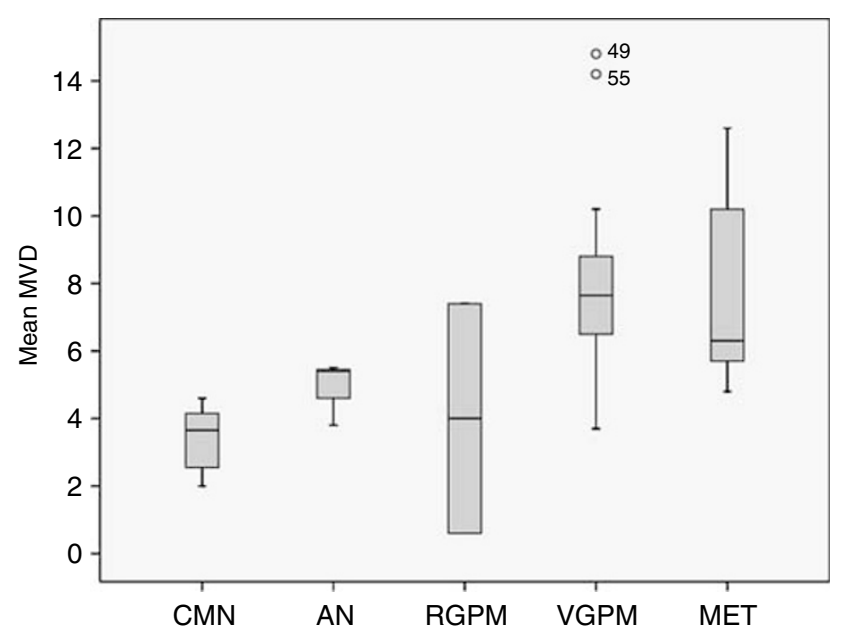

Figure 3 Distribution of mean peritumoral CD105+ microvessel density in the categories of common melanocytic nevi (CMN), atypical, so-called 'dysplastic' nevi (AN); radial growth phase melanomas (RGPM), vertical growth phase melanomas (VGPM) and melanoma metastases (MET). Mean peritumoral microvessel density was significantly higher in primary (both radial and vertical growth phase) and metastatic melanomas in comparison with melanocytic nevi $(P=0.001$, Kruskal-Wallis H-test).

in melanocytes and peripheral and intratumoral lymphatic vessel density, where increased iNOS immunostaining was associated with higher lymphatic vessel density (peritumoral: $R=0.52$, $P=0.001$; intratumoral: $R=0.28, P=0.08$, Spearman's $\rho$-test). Similarly, iNOS expression was associated to peritumoral microvessel density evaluated by CD105 $(R=0.35, P=0.02$, Spearman's $\rho$-test). Conversely, iNOS did not significantly correlate with intratumoral microvessel density $(R=0.20, P=0.21$, Spearman's $\rho$-test $)$.

\section{Discussion}

In the present study, we firstly confirmed our previous observation, ${ }^{14}$ showing a higher iNOS expression in primary and metastatic melanomas in comparison with levels observed in melanocytic 

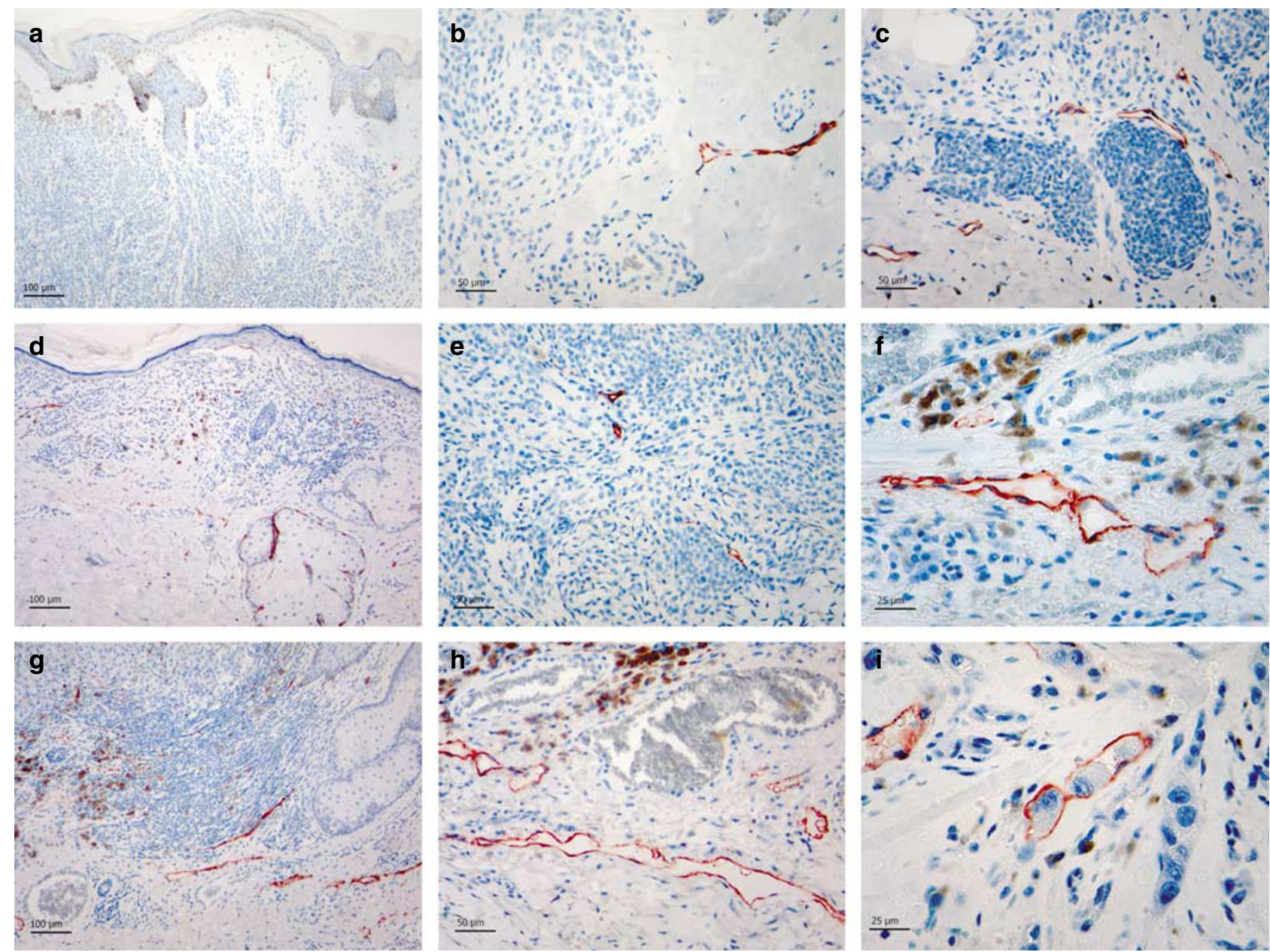

Figure 4 (a) Immunostaining for D2-40 in a common melanocytic nevus highlights rare lymphatic vessels (asterisks) in the upper portions (original magnification $\times 10$; scale bar, $100 \mu \mathrm{m}$ ); (b) perilesional D2-40 + lymphatics in a congenital nevus (original magnification $\times 20$; scale bar, $50 \mu \mathrm{m}$ ); (c) intralesional D2-40 + lymphatics in congenital nevus (original magnification $\times 20$; scale bar, $50 \mu \mathrm{m}$ ); (d) D2-40 + lymphatics in peritumoral location in a RGP melanoma with prominent regression (original magnification $\times 10$; scale bar, $100 \mu \mathrm{m})$; (e) D2-40 + intratumoral lymphatics showing small lumina compressed by melanoma cells in a VGP melanoma (original magnification $\times 20$; scale bar, $50 \mu \mathrm{m}$ ); (f) D2-40 + peritumoral lymphatics showing large open lumina (original magnification $\times 40$; scale bar, $25 \mu \mathrm{m}$ ); (g) tumor invasive front at the periphery of a thick VGP melanomas shows D2-40 + peritumoral vessels (original magnification $\times 10$; scale bar, $100 \mu \mathrm{m}$ ); (h) large, peritumoral lymphatic vessels at the periphery of a thick VGP melanoma; adjacent blood vessels replete with erythrocytes are negative (original magnification $\times 20$; scale bar, $50 \mu \mathrm{m}$ ); (i) melanoma cells within a lymphatic vessel at the periphery of a VGP melanoma (original magnification $\times 40$; scale bar, $25 \mu \mathrm{m}$ ).

nevi, characterized by absent to low iNOS immunostaining. At variance with this finding, a previous report described that all benign congenital and acquired nevi expressed iNOS. ${ }^{17}$ However, as very few nevi expressed cytoplasmic nitrotyrosine,${ }^{17}$ the stable end product of the intracellular reaction of NO with reactive oxygen species, the role of this morphological observation is disputable. In fact, should iNOS be expressed in nevi, it should be functionally inactive, or nevus cells lacking reactive oxygen radicals, do not form peroxynitrite.

Second, we obtained two original observations. On one hand, we observed that in cutaneous melanocytic lesions the levels of iNOS expressed by neoplastic cells correlate with the density of peritumoral microvessels evaluated by CD105 staining. On the other hand, we found that the density of lymphatic vessels in both peritumoral and intratumoral location was associated with the intensity of iNOS staining in tumor cells. These findings support the hypothesis that iNOS is implicated in blood and lymphatic vascular formation in tumor tissues.

In melanomas, NO plays a major role because in early steps of invasion (ie the invasive RGP), it contributes to neoangiogenesis, favoring tumor progression. Previous reports have implicated NO in tumor growth and angiogenesis in cancer. ${ }^{18-20} \mathrm{NO}$ upregulates VEGF production, and VEGF requires sustained NO release for effective angiogenesis. ${ }^{7,21}$ NO-dependent cyclic guanosine monophosphate pathway promotes the activity of VEGF released by tumor cells, ${ }^{22}$ and specific trophic properties of NO on endothelial cells contribute to tumor vascularization $^{2,23}$ and maintenance of tumor blood flow. ${ }^{24}$ 
More recently, it has been showed that NO could induce NF- $\mathrm{KB}$ activity via the generation of peroxynitrite (ONOO-). ${ }^{25}$ Because NF- $\kappa \mathrm{B}$ is the

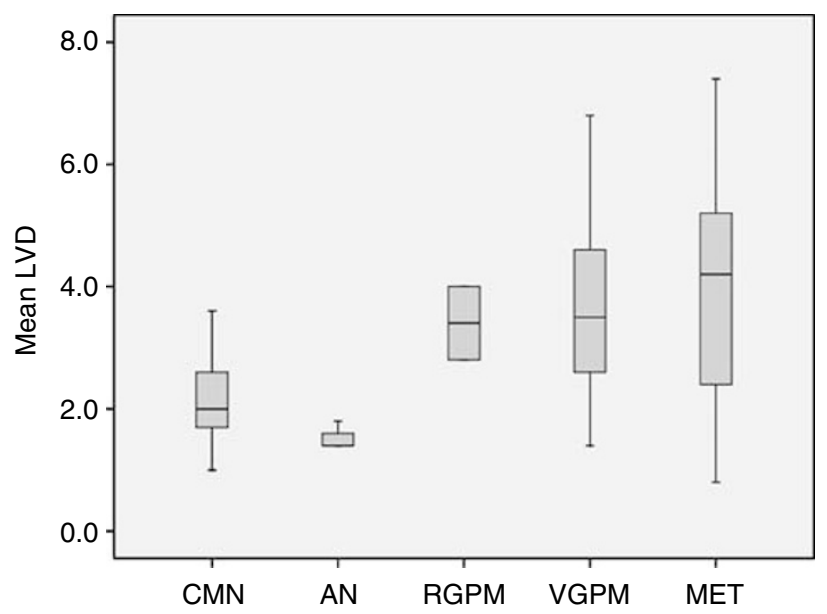

Figure 5 Distribution of mean peritumoral D2-40 lymphatic vessel density in the categories of common melanocytic nevi (CMN), atypical, so-called 'dysplastic' nevi (AN); radial growth phase melanomas (RGPM), vertical growth phase melanomas (VGPM) and melanoma metastases (MET). The number of peritumoral lymphatics was significantly lower in melanocytic nevi as compared with both primary (both in radial and vertical growth phase) and metastatic melanomas $(P=0.01$, Kruskal-Wallis H-test). upstream regulator of iNOS, the two molecules may be arranged in a positive feedback loop directed to amplify the downstream responses of angiogenic factors. ${ }^{26}$

In all tissues including different tumors, important sources of NO are endothelial cells and stromal cells, such as tumor-associated macrophages (TAMs). We recently provided evidence that TAMs of early melanomas show an activated phenotype in which iNOS prevails on arginase. However, in an in vitro model the release of high NO levels by TAMs required that tumor microenvironment contains activated lymphocytes or natural killer cells producing IFN $-\gamma .{ }^{27}$ Thus, it may be possible that also iNOS expressed by nonmelanoma cells contribute to lymphangiogenesis.

Whereas the role of iNOS as a promoter of angiogenesis of blood vessels in different cancers has undergone thorough investigation, the ability of iNOS to control angiogenesis of lymphatic vessels is much less known. NO regulates the vasomotor activity of lymphatic microvessels, ${ }^{8,28}$ inducing dilation, and it may act as a lymphangiogenetic factor through interaction with VEGF-C, as previously demonstrated in breast cancer and head and neck squamous cell carcinomas. ${ }^{5,29}$ Interestingly, VEGF-C-overexpressing melanomas showed enhanced tumor angiogenesis, suggesting a coordinated

Table 4 Studies of lymphangiogenesis and prognosis in primary malignant melanoma

\begin{tabular}{|c|c|c|c|c|}
\hline Series & Cases & Antibodies & $\begin{array}{l}\text { Computer-assisted } \\
\text { morphometric } \\
\text { analysis }\end{array}$ & Main findings \\
\hline Dadras $^{36}$ & 37 & $\begin{array}{l}\text { LYVE-1, CD31, } \\
\text { VEGF-C }\end{array}$ & Yes & $\begin{array}{l}\text { Increased intratumoral LV associated with metastatic } \\
\text { melanoma and correlates with poor DFS. High-relative } \\
\text { LV area was associated with poor DFS and OS. }\end{array}$ \\
\hline Straume $^{37}$ & 220 & $\begin{array}{l}\text { LYVE-1, Podoplanin, } \\
\text { Ki-67 }\end{array}$ & No & $\begin{array}{l}\text { Decreased LV density was present in thicker and more } \\
\text { proliferative melanomas. Increased LV density was } \\
\text { significantly associated with improved patient survival } \\
\text { in multivariate analysis. }\end{array}$ \\
\hline Giorgadze $^{38}$ & 29 & D2-40, CD31 & No & $\begin{array}{l}\text { Intratumoral LV density higher in invasive melanomas } \\
\text { compared to acquired or dysplastic nevi. }\end{array}$ \\
\hline Shields ${ }^{39}$ & 21 & $\begin{array}{l}\text { LYVE-1, CD31, } \\
\text { VEGFR-3, VEGF-C, } \\
\text { VEGF-D }\end{array}$ & No & $\begin{array}{l}\text { Increased LV density associated with metastases. No } \\
\text { comment on survival. }\end{array}$ \\
\hline Valencak $^{40}$ & 120 & Podoplanin, CD31 & No & $\begin{array}{l}\text { Increased LV density was significantly associated with } \\
\text { poor OS and poor DFS (univariate). Increased CD } 31 \text { was } \\
\text { significantly associated with poor DFS and OS in } \\
\text { multivariate analysis. }\end{array}$ \\
\hline Dadras $^{31}$ & 45 & $\begin{array}{l}\text { CD31, LYVE-1, D2-40, } \\
\text { VEGF-C, VEGF-D }\end{array}$ & Yes & $\begin{array}{l}\text { Increased LV density and area in SLN+ cases. LV area } \\
\text { was the most sensitive prognostic marker for SLN } \\
\text { metastasis. Higher VEGF-C expression in SLN+ } \\
\text { melanomas. }\end{array}$ \\
\hline Sahni $^{41}$ & 36 & LYVE-1 & No & $\begin{array}{l}\text { No significant difference in LV density between SLN+ } \\
\text { and SLN- cases. Higher peritumoral LV density in } \\
\text { ulcerated melanomas. }\end{array}$ \\
\hline Massi $^{42}$ & 45 & D2-40, VEGF-C & Yes & $\begin{array}{l}\text { Number and area of LV was significantly higher in } \\
\text { melanomas associated with SLN metastasis. By logistic } \\
\text { regression analysis, intratumoral LV area resulted the } \\
\text { most significant predictor of SLN metastasis }(P=0.04) \text {. } \\
\text { By multivariate analysis, peritumoral LV density } \\
\text { resulted an independent variable affecting OS. }\end{array}$ \\
\hline
\end{tabular}

DFS, disease-free survival; LV, lymphatic vessels; OS, overall survival. 
regulation by this protein of lymphangiogenesis and angiogenesis in melanoma progression. ${ }^{30,31}$

CD105 is an endothelial marker that reacts uniquely with endothelial cells of newly formed vessels, and, specifically of immature tumor blood vessels. ${ }^{32}$ Thus, microvessel density evaluated using a marker of activated endothelial cells, such as CD105, may depict the time-course of the neoangiogenetic process within the tumor. Microvessel density, identified with a CD105 antibody, was significantly higher in melanomas in comparison with melanocytic nevi. In addition, VGP melanomas showed a higher intratumoral microvessel density in comparison with RGP melanomas. A previous report $^{33}$ showed that in 202 VGP melanomas and 68 corresponding metastases, CD105 peritumoral MVD was an independent prognostic factor of the disease. In the present study, we were unable to correlate the increase in microvessel density with prognosis. This may be due to the lower number of cases examined in the present study. However, previous literature have reported controversial findings on the role of angiogenesis as a prognostic factor in melanoma. ${ }^{34}$ Contrasting results might be due to the variability of nonstandardized assessment of tumor vascularity and different detection methods used to visualize tumor-associated blood vessels.

We observed that the number of peritumoral lymphatics was significantly lower in melanocytic nevi as compared with either primary (both in radial and vertical growth phase) or metastatic melanomas. Thus, a 'lymphangiogenic switch' in malignant tumors characterized by overproduction of lymphangiogenic factors and downregulation of lymphangiogenesis inhibitors produced by tumor cells, stromal cells or inflammatory cells may parallel the better known angiogenic switch. We also found a lower number of lymphatic vessels within the tumor mass in comparison with the peritumoral area, and no difference of intratumoral lymphatic vessel density was demonstrated between nevi and melanomas. Studies on murine and human tumors indicated that intratumoral lymphatics are often nonfunctional, ${ }^{35}$ whereas expansion of peritumoral lymphatic vessels could have more importance in the process of tumor dissemination.

Opposing results have been reported on lymphangiogenesis in melanoma (Table 4), possibly due to the diversity of the antibodies used and of methods for evaluation of lymphatic vessel density. ${ }^{31,36-42}$ The recent identification of specific lymphatic markers discriminating lymphatic from blood vessels has provided more accurate results. Recent views point on changes in surface area of lymphatics or tumor cell-LEC interaction on the control of lymphatic metastases. ${ }^{43}$ LEC chemotaxis and proliferation in response to tumor cells (chemotaxis-lymphangiogenesis hypothesis) may occur or LECs may secrete chemotactic agents that attract cancer cells (chemotactic metastasis hypothesis). ${ }^{44}$ Melanoma cells seem to grow more toward regions of high LEC density owing to chemotactic LEC secretions, including the chemokine CCL21. ${ }^{44} \mathrm{We}$ propose that increased iNOS and the possible consequent increased NO levels being associated to an augmented number of lymphatic vessels, might contribute to lymphangiogenesis in melanoma. Mechanistic studies are needed to address the possibility that iNOS control lymphangiogenesis and thus favor the dissemination of lymphatic borne metastases.

\section{Acknowledgement}

This study was financially supported by Fondazione Monte dei Paschi di Siena.

\section{References}

1 Kleinert H, Pautz A, Linker K, et al. Regulation of the expression of inducible nitric oxide synthase. Eur J Pharmacol 2004;500:255-266.

2 Jenkins DC, Charles IG, Thomsen LL, et al. Roles of nitric oxide in tumor growth. Proc Natl Acad Sci USA 1995;92:4392-4396.

3 Cobbs CS, Brenman JE, Aldape KD, et al. Expression of nitric oxide synthase in human central nervous system tumors. Cancer Res 1995;55:727-730.

4 Thomsen LL, Miles DW, Happerfield L, et al. Nitric oxide synthase activity in human breast cancer. Br J Cancer 1995;72:41-44.

5 Franchi A, Massi D, Santucci M, et al. Inducible nitric oxide synthase activity correlates with lymphangiogenesis and vascular endothelial growth factor-C expression in head and neck squamous cell carcinoma. J Pathol 2006;208:439-445.

6 Joshi M, Strandhoy J, White WL. Nitric oxide synthase activity is up-regulated in melanoma cell lines: a potential mechanism for metastases formation. Melanoma Res 1996;6:121-126.

7 Fukumura D, Jain RK. Role of nitric oxide in angiogenesis and microcirculation in tumors. Cancer Metastasis Rev 1998;17:77-89.

8 Ohhashi T, Mizuno R, Ikomi F, et al. Current topics of physiology and pharmacology in the lymphatic system. Pharmacol Ther 2005;105:165-188.

9 Salvucci O, Carsana M, Bersani I, et al. Antiapoptotic role of endogenous nitric oxide in human melanoma cells. Cancer Res 2001;61:318-326.

10 Tang CH, Grimm EA. Depletion of endogenous nitric oxide enhances cisplatin-induced apoptosis in a p53dependent manner in melanoma cell lines. J Biol Chem 2004;279:288-298.

11 Zheng M, Ekmekcioglu S, Walch ET, et al. Inhibition of nuclear factor-kappaB and nitric oxide by curcumin induces G2/M cell cycle arrest and apoptosis in human melanoma cells. Melanoma Res 2004;14:165-171.

12 Tschugguel W, Pustelnik T, Lass $\mathrm{H}$, et al. Inducible nitric oxide synthase (iNOS) expression may predict distant metastasis in human melanoma. Br J Cancer 1999;79:1609-1612.

13 Ekmekcioglu S, Ellerhorst J, Smid CM, et al. Inducible nitric oxide synthase and nitrotyrosine in human 
metastatic melanoma tumors correlate with poor survival. Clin Cancer Res 2000;6:4768-4775.

14 Massi D, Franchi A, Sardi I, et al. Inducible nitric oxide synthase expression in benign and malignant cutaneous melanocytic lesions. J Pathol 2001;194: 194-200.

15 Ekmekcioglu S, Ellerhorst JA, Mumm JB, et al. Negative association of melanoma differentiationassociated gene (mda-7) and inducible nitric oxide synthase (iNOS) in human melanoma: MDA-7 regulates iNOS expression in melanoma cells. Mol Cancer Ther 2003;2:9-17.

16 Ekmekcioglu S, Ellerhorst JA, Prieto VG, et al. Tumor iNOS predicts poor survival for stage III melanoma patients. Int J Cancer 2006;119:861-866.

17 Ahmed B, Van Den Oord JJ. Expression of the inducible isoform of nitric oxide synthase in pigment cell lesions of the skin. Br J Dermatol 2000;142: 432-440.

18 Ambs S, Merriam WG, Bennett WP, et al. Frequent nitric oxide synthase-2 expression in human colon adenomas: implication for tumor angiogenesis and colon cancer progression. Cancer Res 1998;58: 334-341.

19 Gallo O, Masini E, Morbidelli L, et al. Role of nitric oxide in angiogenesis and tumor progression in head and neck cancer. J Natl Cancer Inst 1998;90: 587-596.

20 Reveneau S, Arnould L, Jolimoy G, et al. Nitric oxide synthase in human breast cancer is associated with tumor grade, proliferation rate, and expression of progesterone receptors. Lab Invest 1999;79:1215-1225.

21 Ziche M, Morbidelli L, Choudhuri R, et al. Nitric oxide synthase lies downstream from vascular endothelial growth factor-induced but not basic fibroblast growth factor-induced angiogenesis. J Clin Invest 1997;99: 2625-2634

22 Lin Z, Chen S, Ye C, et al. Nitric oxide synthase expression in human bladder cancer and its relation to angiogenesis. Urol Res 2003;31:232-235.

23 Maeda H, Noguchi Y, Sato K, et al. Enhanced vascular permeability in solid tumor is mediated by nitric oxide and inhibited by both new nitric oxide scavenger and nitric oxide synthase inhibitor. Jpn J Cancer Res 1994;85:331-334.

24 Tozer GM, Prise VE, Chaplin DJ. Inhibition of nitric oxide synthase induces a selective reduction in tumor blood flow that is reversible with L-arginine. Cancer Res 1997;57:948-955.

25 Marshall HE, Merchant K, Stamler JS. Nitrosation and oxidation in the regulation of gene expression. FASEB J 2000;14:1889-1900.

26 Nam HY, Choi BH, Lee JY, et al. The role of nitric oxide in the particulate matter (PM2.5)-induced NFkappaB activation in lung epithelial cells. Toxicol Lett 2004; 148:95-102.

27 Massi D, Marconi C, Franchi A, et al. Arginine metabolism in tumor-associated macrophages in cutaneous malignant melanoma: evidence from human and experimental tumors. Hum Pathol 2007;38:1516-1525.

28 Mizuno R, Koller A, Kaley G. Regulation of the vasomotor activity of lymph microvessels by nitric oxide and prostaglandins. Am J Physiol 1998;274: R790-R796.
29 Nakamura Y, Yasuoka H, Tsujimoto $M$, et al. Nitric oxide in breast cancer: induction of vascular endothelial growth factor-C and correlation with metastasis and poor prognosis. Clin Cancer Res 2006;12: 1201-1207.

30 Skobe M, Hamberg LM, Hawighorst T, et al. Concurrent induction of lymphangiogenesis, angiogenesis, and macrophage recruitment by vascular endothelial growth factor-C in melanoma. Am J Pathol 2001;159: 893-903.

31 Dadras SS, Lange-Asschenfeldt B, Velasco P, et al. Tumor lymphangiogenesis predicts melanoma metastasis to sentinel lymph nodes. Mod Pathol 2005;18:1232-1242.

32 Fonsatti E, Altomonte M, Nicotra MR, et al. Endoglin (CD105): a powerful therapeutic target on tumorassociated angiogenetic blood vessels. Oncogene 2003;22:6557-6563.

33 Straume O, Akslen LA. Expression of vascular endothelial growth factor, its receptors (FLT-1, KDR) and TSP-1 related to microvessel density and patient outcome in vertical growth phase melanomas. Am J Pathol 2001;159:223-235.

34 Streit M, Detmar M. Angiogenesis, lymphangiogenesis, and melanoma metastasis. Oncogene 2003;22: 3172-3179.

35 Padera TP, Kadambi A, di Tomaso E, et al. Lymphatic metastasis in the absence of functional intratumor lymphatics. Science 2002;296:1883-1886.

36 Dadras SS, Paul T, Bertoncini J, et al. Tumor lymphangiogenesis: a novel prognostic indicator for cutaneous melanoma metastasis and survival. Am J Pathol 2003;162:1951-1960.

37 Straume O, Jackson DG, Akslen LA. Independent prognostic impact of lymphatic vessel density and presence of low-grade lymphangiogenesis in cutaneous melanoma. Clin Cancer Res 2003;9:250-256.

38 Giorgadze TA, Zhang PJ, Pasha T, et al. Lymphatic vessel density is significantly increased in melanoma. J Cutan Pathol 2004;31:672-677.

39 Shields JD, Borsetti M, Rigby $\mathrm{H}$, et al. Lymphatic density and metastatic spread in human malignant melanoma. Br J Cancer 2004;90:693-700.

40 Valencak J, Heere-Ress E, Kopp T, et al. Selective immunohistochemical staining shows significant prognostic influence of lymphatic and blood vessels in patients with malignant melanoma. Eur J Cancer 2004;40:358-364.

41 Sahni D, Robson A, Orchard G, et al. The use of LYVE-1 antibody for detecting lymphatic involvement in patients with malignant melanoma of known sentinel node status. J Clin Pathol 2005;58:715-721.

42 Massi D, Puig S, Franchi A, et al. Tumour lymphangiogenesis is a possible predictor of sentinel lymph node status in cutaneous melanoma: a case-control study. J Clin Pathol 2006;59:166-173.

43 Saharinen P, Tammela T, Karkkainen MJ, et al. Lymphatic vasculature: development, molecular regulation and role in tumor metastasis and inflammation. Trends Immunol 2004;25:387-395.

44 Shields JD, Emmett MS, Dunn DB, et al. Chemokinemediated migration of melanoma cells towards lymphatics-a mechanism contributing to metastasis. Oncogene 2007;26:2997-3005. 